\title{
Article \\ Effect of Monosodium Glutamate on Saltiness and Palatability Ratings of Low-Salt Solutions in Japanese Adults According to Their Early Salt Exposure or Salty Taste Preference
}

\author{
Rieko Morita ${ }^{1}$, Masanori Ohta ${ }^{1, *} \mathbb{0}$, Yoko Umeki ${ }^{1}$, Akiko Nanri ${ }^{1}$, Takuya Tsuchihashi ${ }^{2}$ and Hitomi Hayabuchi ${ }^{3}$ \\ 1 Graduate School of Health and Environmental Sciences, Fukuoka Women's University, \\ Fukuoka 813-8529, Japan; r.morita@fwu.ac.jp (R.M.); umeki@fwu.ac.jp (Y.U.); nanri@fwu.ac.jp (A.N.) \\ 2 Steel Memorial Yawata Hospital, Kitakyushu, Fukuoka 805-8508, Japan; takuya.tuti@gmail.com \\ 3 Department of Food Science and Nutrition, Faculty of Human Life and Environment, Nara Women's \\ University, Nara 630-8506, Japan; h.hayabuchi@cc.nara-wu.ac.jp \\ * Correspondence: m-ohta@fwu.ac.jp; Tel.: +81-92-661-2411
}

Citation: Morita, R.; Ohta, M.; Umeki, Y.; Nanri, A.; Tsuchihashi, T.; Hayabuchi, H. Effect of Monosodium Glutamate on Saltiness and Palatability Ratings of Low-Salt Solutions in Japanese Adults According to Their Early Salt Exposure or Salty Taste Preference. Nutrients 2021, 13, 577. https:// doi.org/10.3390/nu13020577

Academic Editors

Masanari Kuwabara and

Albertino Bigiani

Received: 20 December 2020

Accepted: 5 February 2021

Published: 9 February 2021

Publisher's Note: MDPI stays neutra with regard to jurisdictional claims in published maps and institutional affiliations.

Copyright: (c) 2021 by the authors. Licensee MDPI, Basel, Switzerland. This article is an open access article distributed under the terms and conditions of the Creative Commons Attribution (CC BY) license (https:/ / creativecommons.org/licenses/by/ $4.0 /)$.

\begin{abstract}
Using umami can help reduce excessive salt intake, which contributes to cardiovascular disease. Differences in salt-exposed environment at birth and preference for the salty taste might affect the sense of taste. Focusing on these two differences, we investigated the effect of monosodium L-glutamate (MSG) on the saltiness and palatability of low-salt solutions. Japanese participants (64 men, 497 women, aged $19-86$ years) tasted $0.3 \%, 0.6 \%$, and $0.9 \% \mathrm{NaCl}$ solutions with or without $0.3 \%$ MSG to evaluate saltiness and palatability. They were also asked about their birthplace, personal salty preference, and family salty preference. Adding MSG enhanced saltiness, especially in the $0.3 \%$ $\mathrm{NaCl}$ solution, while the effect was attenuated in the $0.6 \%$ and $0.9 \% \mathrm{NaCl}$ solutions. Palatability was rated higher with MSG than without MSG for each $\mathrm{NaCl}$ solution, with a peak value for the $0.3 \%$ $\mathrm{NaCl}$ solution with MSG. There was no difference in the effect of umami ingredients on palatability between the average salt intake by the regional block at birth and salty preference (all $p>0.05$ ). Thus, adding an appropriate amount of umami ingredients can facilitate salt reduction in diet while maintaining palatability regardless of the salt-exposed environment in early childhood or salty preference.
\end{abstract}

Keywords: salt reduction; umami; palatability; taste preference; generation; regional difference

\section{Introduction}

The importance of sodium reduction as a practical prevention measure for cardiovascular disease is widely known [1,2]. However, salt intake in almost all countries exceeds the World Health Organization's (WHO's) recommendation of $<5 \mathrm{~g} /$ day [3]. High salt intake has been reported as a leading dietary risk factor in over 3 million deaths and 70 million disability-adjusted life years in 2017 [4]. Salt reduction is an urgent issue worldwide [5].

In Japan, the National Health and Nutrition Survey in 2019 reported that the salt intake of Japanese adult men was $10.9 \mathrm{~g}$ /day and that of adult women was $9.3 \mathrm{~g} /$ day [6]. These amounts are approximately twice the amount recommended by the WHO. Since the 1950s, stroke has been the leading cause of death in Japan [7]. Tomonari et al., in their investigation of the mutual relationship among salt intake, blood pressure, and stroke mortality in 12 regions of Japan, reported that salt intake was an independent factor for stroke mortality [8]. Salt intake has been found to be higher in Tohoku than in other regions of Japan; indeed, in 1980, it accounted for the highest salt intake (15.8 g/day, Table 1). The intake of miso and pickles has also been reported as higher in Tohoku than in other regions [9]. 
Table 1. The average amount and level of salt intake in 1980, 1990, and 2000 for 12 regional blocks in Japan along with the number of participants born in each regional block.

\begin{tabular}{|c|c|c|c|c|c|c|c|c|c|c|}
\hline \multirow{3}{*}{$\begin{array}{c}\text { Regional } \\
\text { Block }^{+}\end{array}$} & \multirow{3}{*}{$\begin{array}{l}\text { Name of } \\
\text { Prefecture }\end{array}$} & \multicolumn{3}{|c|}{1980} & \multicolumn{3}{|c|}{1990} & \multicolumn{3}{|c|}{2000} \\
\hline & & \multicolumn{2}{|c|}{ Salt Intake } & \multirow{2}{*}{$N^{\S}$} & \multicolumn{2}{|c|}{ Salt Intake } & \multirow{2}{*}{$N^{\mathbb{T I}}$} & \multicolumn{2}{|c|}{ Salt Intake } & \multirow{2}{*}{$N^{++}$} \\
\hline & & Average (g/Day) & Level ₹ & & Average (g/Day) & Level ‡ & & Average (g/Day) & Level $\ddagger$ & \\
\hline Hokkaido & $\begin{array}{c}\text { Hokkaido } \\
\text { Aomori, Iwate, }\end{array}$ & 14.4 & $\mathrm{H}$ & 2 & 12.7 & $\mathrm{M}$ & 1 & 12.3 & $\mathrm{~L}$ & 2 \\
\hline Tohoku & $\begin{array}{l}\text { Miyagi, Akita, } \\
\text { Yamagata, } \\
\text { Fukushima }\end{array}$ & 15.8 & $\mathrm{H}$ & 33 & 13.5 & $\mathrm{H}$ & 7 & 13.8 & $\mathrm{H}$ & 19 \\
\hline Kanto-1 & $\begin{array}{l}\text { Saitama, Chiba, } \\
\text { Tokyo, Kanagawa } \\
\text { Ibaraki, Tochigi, }\end{array}$ & 12.7 & M & 22 & 12.5 & $\mathrm{~L}$ & 32 & 12.6 & M & 16 \\
\hline Kanto-2 & $\begin{array}{l}\text { Gunma, } \\
\text { Yamanashi, } \\
\text { Nagano }\end{array}$ & 15.4 & $\mathrm{H}$ & 6 & 13.6 & $\mathrm{H}$ & 7 & 13.5 & $\mathrm{H}$ & 10 \\
\hline Hokuriku & $\begin{array}{l}\text { Niigata, Toyama, } \\
\text { Ishikawa, Fukui }\end{array}$ & 14.2 & $\mathrm{H}$ & 6 & 12.8 & M & 5 & 12.8 & M & 2 \\
\hline Tokai & $\begin{array}{l}\text { Gifu, Aichi, Mie, } \\
\text { Shizuoka }\end{array}$ & 11.8 & L & 27 & 12.1 & $\mathrm{~L}$ & 17 & 12.4 & $\mathrm{~L}$ & 22 \\
\hline Kinki-1 & $\begin{array}{l}\text { Kyoto, Osaka, } \\
\text { Hyogo }\end{array}$ & 10.9 & L & 10 & 11.8 & L & 6 & 11.6 & L & 3 \\
\hline Kinki-2 & $\begin{array}{c}\text { Nara, Wakayama, } \\
\text { Shiga } \\
\text { Tottori, Shimane, }\end{array}$ & 11.5 & L & 9 & 13.4 & $\mathrm{H}$ & 4 & 11.2 & $\mathrm{~L}$ & 1 \\
\hline Chugoku & $\begin{array}{l}\text { Okayama, } \\
\text { Hiroshima, } \\
\text { Yamaguchi } \\
\text { Tokushima, }\end{array}$ & 12.3 & L & 27 & 12.5 & L & 14 & 11.9 & $\mathrm{~L}$ & 14 \\
\hline Shikoku & $\begin{array}{l}\text { Kagawa, Ehime, } \\
\text { Kochi }\end{array}$ & 12.0 & $\mathrm{~L}$ & 1 & 12.3 & $\mathrm{~L}$ & 2 & 12.0 & $\mathrm{~L}$ & 1 \\
\hline $\begin{array}{c}\text { Kita } \\
\text { (Northern) } \\
\text { Kyushu }\end{array}$ & $\begin{array}{l}\text { Fukuoka, Saga, } \\
\text { Nagasaki, Oita }\end{array}$ & 13.0 & M & 121 & 11.6 & L & 9 & 11.6 & L & 18 \\
\hline $\begin{array}{l}\text { Minami } \\
\text { (Southern) } \\
\text { Kyushu }\end{array}$ & $\begin{array}{l}\text { Kumamoto, } \\
\text { Miyazaki, } \\
\text { Kagoshima, } \\
\text { Okinawa }\end{array}$ & 13.6 & $\mathrm{H}$ & 44 & 13.0 & M & 37 & 11.0 & $\mathrm{~L}$ & 4 \\
\hline & & \multicolumn{2}{|c|}{$\begin{array}{l}\text { the born-before-the } 1980 \mathrm{~s} \\
\text { group }(N)\end{array}$} & 308 & \multicolumn{2}{|c|}{$\begin{array}{l}\text { the born-in-the 1990s group } \\
(N)\end{array}$} & 141 & \multicolumn{2}{|c|}{$\begin{array}{l}\text { the born-in-the 2000s group } \\
(N)\end{array}$} & 112 \\
\hline
\end{tabular}

t: Regional blocks categorized by the National Nutrition Survey in Japan, and are listed in order from North to South. ‡: Participants are classified into three levels according to the average salt intake by regional block at birth (L: low $<12.6 \mathrm{~g}$, M: middle $\geq 12.6$ and $<13.4 \mathrm{~g}$, $\mathrm{H}:$ high $\geq 13.4 \mathrm{~g}$ ). §: Number of participants born in each regional block before 1989. II: Number of participants born in each regional block during 1990-1999. +t: Number of participants born in each regional block during 2000-2001.

Takachi et al. reported that self-reported taste preferences for miso soup were significantly associated with 24-h urinary sodium excretion and daily salt intake [10]. Food preferences established in early childhood continue into later life [11]. Salt preference is affected by the dietary habits of pregnant mothers and experiences with food during the first year of life [11,12]. Therefore, those who experienced high salt exposure during early childhood may have a high salty taste preference. Moreover, salty taste preference can also be influenced by the family's salt use habits [13,14]. Many studies have reported that the use of glutamate is an effective way to reduce salt intake while maintaining the palatability of food $[15,16]$. Soup is a common dish worldwide, and miso soup is a daily food in Japan. It has been reported that glutamates such as monosodium glutamate (MSG) and calcium diglutamate (CDG) enhance the palatability of low-salt soups when used as a solvent, such as in clear soup, pumpkin soup, and chicken broth, and contribute to salt reduction [17-19]. Umami taste perception varies significantly among individuals. The differences in sensitivity can result from genetic variations in taste receptors [20], familiarity with umami [21,22], or hormonal levels [23]. Furthermore, umami taste perception can be enhanced by repeated exposure $[20,24]$. The interaction between umami and salt perception, however, remains unclear.

The effect of using MSG on low-salt solutions can be influenced by the salt exposure environment involving early childhood and family salty preference. However, no studies have investigated the relationship of the effect of umami in low-salt solutions with salt exposure environment in early childhood and salty taste preference. In this study, we focused 
on the differences between salt exposure environment in early childhood and current salty taste preference, and aimed to investigate the effect of adding sodium glutamate on the saltiness and palatability of low-salt solutions.

\section{Materials and Methods}

\subsection{Study Design}

This study was conducted from July 2017 to November 2018 in Japan. Sensory evaluations were performed and a questionnaire survey was administered at eight universities and 11 health seminars in 13 prefectures of Japan (Aomori, Miyagi, Tokyo, Chiba, Saitama, Kanagawa, Shizuoka, Nara, Hiroshima, Fukuoka, Nagasaki, Kagoshima, and Okinawa). The study protocol and material have been described in detail elsewhere [25].

These experiments were approved by the Research Ethics Committee at Fukuoka Women's University (No. 2016-31) for students and the Research Ethics Review Committee at Nara Women's University (No. 18-02) for attendees of health seminars. All participants provided signed informed consent prior to the study. The approved experiments were registered in the University Hospital Medical Information Network Clinical Trials Registry (UMIN000035280 and UMIN000035289).

\subsection{Participants}

The participants were 259 students from eight universities, and 392 attendees from 11 health seminars. From a total of 651 participants, we excluded 20 participants who had a taste disorder, eight participants who did not answer the question on taste disorder in the questionnaire, and 40 participants who did not complete the sensory evaluation test. In addition, we excluded 14 participants who did not answer the questionnaire, and eight participants who were not from Japan. Ultimately, 561 participants (64 men and 497 women) were included in the analysis. The flow chart of the participants is shown in Figure 1.

\subsection{Sensory Evaluation}

Previously, we examined the saltiness, umami, and palatability of 48 aqueous solutions containing eight different concentrations of $\mathrm{NaCl}(0.2,0.3,0.4,0.5,0.6,0.7,0.8$, and $0.9 \%)$ and six different concentrations of MSG $(0.1,0.2,0.3,0.4,0.5$, and $0.6 \%)$ by sensory evaluation among female students and teachers [26]. Based on the results of the previous examination, six samples were prepared, which included $0.3 \%, 0.6 \%$, and $0.9 \% \mathrm{NaCl}$ solutions with or without $0.3 \%$ MSG. Saltiness and palatability ratings were assessed using a visual analogue scale (VAS) [27]. The VAS scale represented a minimum rating at the left end (not at all salty or extremely unpalatable) and a maximum rating at the right end (extremely salty or palatable) for each sample. Each solution was tested twice, with the order of the samples being changed after 15 min or more. The participants were asked to rinse their mouths with water before and after each sample evaluation.

\subsection{Questionnaire Survey}

Using a questionnaire, the participants were inquired about their individual characteristics of sex, age (years), smoking habit (current, former, and never), use of medication (yes and no), and birthplace. In addition, they were inquired about the degree of personal salty taste preference (very light, light, middle, strong, and very strong), degree of family salty taste preference (very light, light, middle, strong, and very strong), and degree of salt reduction efforts (always, sometimes, rarely, and never).

\subsection{Average Salt Intake by Regional Block at Birth}

In the present study, the average salt intake by regional block at birth was defined as the environmental indicator of salt exposure in early childhood. The average salt intake was obtained from the results of the National Nutrition Survey from 1980 to 2000, which has been conducted every year since 1946. There were no data on the average salt intake 
by regional block prior to 1979 . We adopted the data of salt intake in 1980, as the salt intake might have been higher before 1980 than after 1980, according to annual changes in the salt intake of the Japanese from 1972 to 1980 [9]. Participants were divided into three groups based on generations: the born-in-the-2000s group (from 19 to 20 years old), the born-in-the-1990s group (from 21 to 30 years old), and the born-before-the-1980s group (over 31 years old). After that, the average salt intake data for 2000, 1990, and 1980 was used for the born-in-the-2000s group, the born-in-1990s group, and the born-before-1980s group, respectively. The birthplaces were also divided into 12 regional blocks according to the National Nutrition Survey in Japan (Table 1). Eventually, the averages of salt intake by regional block at birth in 1980, 1990, and 2000 were obtained for the 12 regional blocks.

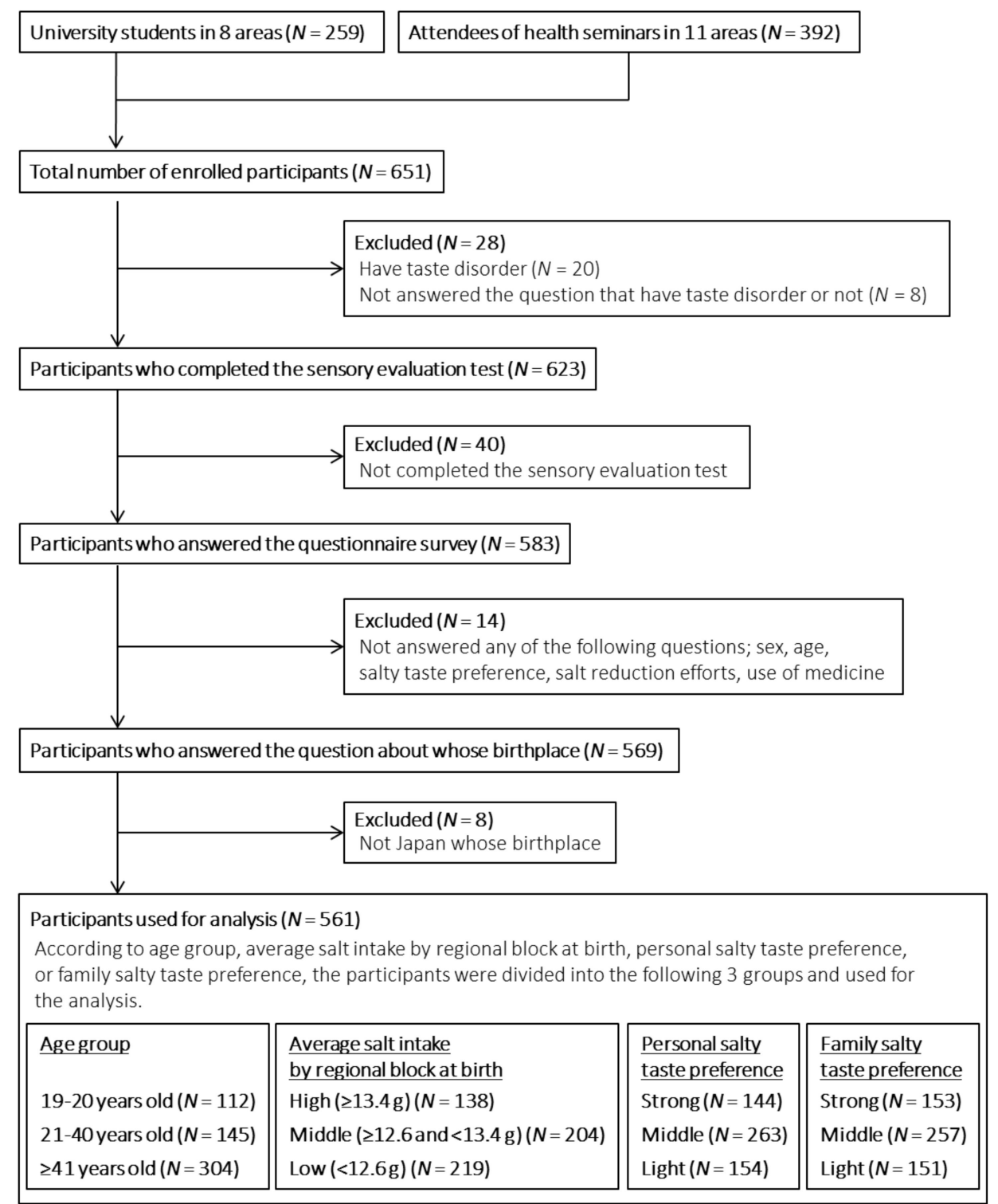

Figure 1. Flow chart on the analyzed participants.

\subsection{Statistical Analysis}

The average salt intake by regional block at birth was coded using the tertile as low (less than $12.6 \mathrm{~g} /$ day), middle (over $12.6 \mathrm{~g} /$ day and less than $13.4 \mathrm{~g} /$ day), and high (over $13.4 \mathrm{~g} /$ day). Moreover, degrees of personal and family salty taste preference were categorized into three groups: light (very light and light), middle, and strong (very strong and strong). The first and second taste evaluations of the saltiness and palatability of 
the six solutions were averaged. Chi-square tests were used to analyze the difference between sex and age groups. The normality of data distribution was tested using the Shapiro-Wilk test, and the distribution was not normal. Normal distribution methods were used in this study, because the statistical power was set such that VAS ratings were not concentrated around either extreme of the scale [28]. Repeated measures analysis of variance (ANOVA) was used to compare saltiness or palatability ratings of the six solutions. Then, pairwise comparisons were made using Tukey's honestly significance difference procedure. In addition, analysis of covariance (ANCOVA) was employed to compare the saltiness or palatability ratings of each group based on sex, age group, salt intake by regional block at birth, personal salty taste preference, and family salty taste preference for the six solutions adjusted for sex, age group (19-20 years, $21-40$ years, and $\geq 41$ years), smoking habit (current, former, and never), salt reduction efforts (always, sometimes, and rarely/never), and use of medicine (yes and no). Statistical significance was defined as $p<0.05$. Statistical analysis was conducted using JMP statistical software (JMP Pro 15.1.0, SAS Institute Inc., Cary, NC, USA).

\section{Results}

\subsection{Characteristics of the Participants}

Table 2 presents the characteristics of the participants by sex and age groups. The majority of the participants were female (88.6\%) and never smokers $(92.5 \%)$. The percentage of participants who were over 41 years old was $54.2 \%$ (mean \pm SD: $45.45 \pm 23.99$ ). The percentage of participants with a high salt intake by regional block at birth was higher for the over 41-year-old age group than for the other age groups. Regarding salt reduction efforts, $72.5 \%$ participants answered that they engaged in such efforts "always" or "sometimes" (approximately 50\% of the over 41-year-old age group). Thirty-four percent of the participants were taking medications, and this was particularly noticeable in the over 41-year-old age group (87.4\%).

Table 2. Characteristics of the study participants according to sex and age.

\begin{tabular}{|c|c|c|c|c|c|c|c|c|c|c|c|c|c|c|}
\hline \multirow[b]{3}{*}{ All } & \multirow{2}{*}{\multicolumn{2}{|c|}{ All N (\%) }} & \multicolumn{4}{|c|}{ Sex } & \multirow{4}{*}{$\begin{array}{c}p \text { Value } \ddagger \\
<0.001\end{array}$} & \multicolumn{6}{|c|}{ Age } & \multirow{3}{*}{$p$ Value ${ }^{\S}$} \\
\hline & & & \multicolumn{2}{|c|}{ Male $N(\%)$} & \multicolumn{2}{|c|}{ Female $N(\%)$} & & \multicolumn{2}{|c|}{$19-20 N(\%)$} & \multicolumn{2}{|c|}{$21-40 N(\%)$} & \multicolumn{2}{|c|}{$\geq 41 N(\%)$} & \\
\hline & 561 & $(100)$ & 64 & $(100)$ & 497 & $(100)$ & & 112 & $(100)$ & 145 & $(100)$ & 304 & $(100)$ & \\
\hline Age group (years) & & & & & & & & & & & & & & \\
\hline $19-20$ & 112 & $(20.0)$ & 5 & $(7.8)$ & 107 & $(21.5)$ & & & & & & & & \\
\hline $21-40$ & 145 & $(25.8)$ & 3 & $(4.7)$ & 142 & $(28.6)$ & & & & & & & & \\
\hline$\geq 41$ & 304 & $(54.2)$ & 56 & (87.5) & 248 & (49.9) & & & & & & & & \\
\hline \multicolumn{3}{|c|}{ Salt intake by regional block at birth ${ }^{+}$} & & & & & $<0.05$ & & & & & & & $<0.001$ \\
\hline High $(\geq 13.4 \mathrm{~g})$ & 138 & $(24.6)$ & 14 & $(21.9)$ & 124 & $(24.9)$ & & 29 & $(25.9)$ & 18 & $(12.4)$ & 91 & $(29.9)$ & \\
\hline Middle $(\geq 12.6$ and $<13.4 \mathrm{~g})$ & 204 & $(36.4)$ & 33 & (51.6) & 171 & (34.4) & & 18 & $(16.1)$ & 45 & $(31.0)$ & 141 & $(46.4)$ & \\
\hline Low $(<12.6 \mathrm{~g})$ & 219 & $(39.0)$ & 17 & $(26.6)$ & 202 & $(40.6)$ & & 65 & $(58.0)$ & 82 & $(56.6)$ & 72 & $(23.7)$ & \\
\hline \multicolumn{3}{|l|}{ Personal salty taste preference } & & & & & $<0.001$ & & & & & & & 0.019 \\
\hline Strong & 144 & $(25.7)$ & 30 & $(46.9)$ & 114 & (22.9) & & 29 & $(25.9)$ & 46 & $(31.7)$ & 69 & (22.7) & \\
\hline Middle & 263 & $(46.9)$ & 21 & $(32.8)$ & 242 & $(48.7)$ & & 60 & $(53.6)$ & 68 & $(46.9)$ & 135 & $(44.4)$ & \\
\hline Light & 154 & $(27.5)$ & 13 & (20.3) & 141 & $(28.4)$ & & 23 & $(20.5)$ & 31 & $(21.4)$ & 100 & $(32.9)$ & \\
\hline \multicolumn{3}{|l|}{ Family salty taste preference } & & & & & 0.818 & & & & & & & $<0.001$ \\
\hline Strong & 153 & $(27.3)$ & 19 & $(29.7)$ & 134 & $(27.0)$ & & 37 & $(33.0)$ & 56 & $(38.6)$ & 60 & (19.7) & \\
\hline Middle & 257 & $(45.8)$ & 27 & $(42.2)$ & 230 & $(46.3)$ & & 57 & $(50.9)$ & 58 & $(40.0)$ & 142 & $(46.7)$ & \\
\hline Light & 151 & $(26.9)$ & 18 & $(28.1)$ & 133 & $(26.8)$ & & 18 & $(16.1)$ & 31 & $(21.4)$ & 102 & (33.6) & \\
\hline \multicolumn{3}{|l|}{ Salt reduction efforts } & & & & & 0.041 & & & & & & & $<0.001$ \\
\hline Always & 160 & $(28.5)$ & 14 & $(21.9)$ & 146 & $(29.4)$ & & 11 & $(9.8)$ & 11 & $(7.6)$ & 138 & $(45.4)$ & \\
\hline Sometimes & 247 & $(44.0)$ & 24 & (37.5) & 223 & (44.9) & & 46 & (41.1) & 82 & $(56.6)$ & 119 & (39.1) & \\
\hline Rarely/Never & 154 & $(27.5)$ & 26 & $(40.6)$ & 128 & $(25.8)$ & & 55 & $(49.1)$ & 52 & $(35.9)$ & 47 & (15.5) & \\
\hline \multicolumn{3}{|l|}{ Smoking habit } & & & & & $<0.001$ & & & & & & & $<0.001$ \\
\hline Current & 14 & $(2.5)$ & 7 & $(10.9)$ & 7 & (1.4) & & 2 & $(1.8)$ & 2 & $(1.4)$ & 10 & $(3.3)$ & \\
\hline Former & 28 & $(5.0)$ & 20 & (31.3) & 8 & (1.6) & & 0 & (0) & 0 & (0) & 28 & (9.2) & \\
\hline Never & 519 & $(92.5)$ & 37 & (57.8) & 482 & (97.0) & & 110 & $(98.2)$ & 143 & (98.6) & 266 & (87.5) & \\
\hline \multirow{3}{*}{ Medication } & & & & & & & $<0.001$ & & & & & & & $<0.001$ \\
\hline & 191 & $(34.0)$ & 35 & (54.7) & 156 & (31.4) & & 6 & (5.4) & 18 & (12.4) & 167 & (54.9) & \\
\hline & 370 & $(66.0)$ & 29 & (45.3) & 341 & (68.6) & & 106 & $(94.6)$ & 127 & (87.6) & 137 & $(45.1)$ & \\
\hline
\end{tabular}

t: Participants are classified into three levels according to the average salt intake by 12 regional blocks in 1980, 1990, and 2000 from the National Nutrition Survey in Japan (low: $<12.6 \mathrm{~g}$, middle: $\geq 12.6$ and $<13.4 \mathrm{~g}$, and high: $\geq 13.4 \mathrm{~g}$ ). $\ddagger$ : $p$ for the comparisons between men and women, $\S: p$ for the comparisons between the three age groups (19-20 years, 21-40 years, and $\geq 41$ years) with the use of chi-square tests. 


\subsection{Saltiness}

The means and standard errors (SEs) of saltiness VAS ratings by sex, age groups, the three levels of salt intake by regional block at birth, and the three levels of salty taste preference are shown in Table 3. Repeated measures ANOVA results showed significant differences in the saltiness ratings of the six solutions among all groups based on sex, age groups, the three levels of salt intake by regional block at birth, and the three levels of salty taste preference (all $p<0.001$ ). The higher the $\mathrm{NaCl}$ concentration, the higher was the saltiness rating. The post-hoc test results showed that the $0.3 \% \mathrm{NaCl}$ solutions with MSG showed significantly higher saltiness ratings than those without MSG in all groups (all $p<0.05$ ). The $0.6 \% \mathrm{NaCl}$ solution with MSG showed a significantly higher rating than the solution without MSG in the 21-40-years-old age group $(p<0.05)$. ANCOVA results showed that there were significantly different ratings for each $\mathrm{NaCl}$ solution with and without MSG among the three age groups, except for the rating for the $0.3 \% \mathrm{NaCl}$ solution alone $(0.3 \% \mathrm{NaCl}$ alone, $p=0.304$; other solutions, $p<0.001)$, with its lowest ratings being in the over 41-years-old age group. As for salt intake by regional block at birth, there was a significantly different rating for the $0.9 \% \mathrm{NaCl}$ solution with MSG among the three groups ( $p=0.008)$, and the saltiness ratings of the low-level group were higher than those of the other groups for all solutions. Additionally, with regard to personal and family salty taste preference, there were significantly different ratings for the $0.3 \% \mathrm{NaCl}$ solution without MSG among the three groups (personal salty taste preference, $p=0.002$; family salty taste preference, $p=0.028$ ), and the ratings of the strong groups for the $0.3 \% \mathrm{NaCl}$ solution without MSG were lower than those of other groups. 
Table 3. Saltiness visual analogue scale (VAS) ratings by sex, age, salt intake by regional block at birth, and salty taste preference.

\begin{tabular}{|c|c|c|c|c|c|c|c|c|}
\hline & \multirow[b]{2}{*}{$N$} & \multicolumn{2}{|c|}{$0.3 \% \mathrm{NaCl}$} & \multicolumn{2}{|c|}{$0.6 \% \mathrm{NaCl}$} & \multicolumn{2}{|c|}{$0.9 \% \mathrm{NaCl}$} & \multirow[b]{2}{*}{$p$ Value $\ddagger$} \\
\hline & & -MSG & +MSG & -MSG & +MSG & -MSG & +MSG & \\
\hline All & 561 & $23.51 \pm 0.65^{\mathrm{a}}$ & $39.28 \pm 0.73^{b}$ & $55.81 \pm 0.72^{c}$ & $58.24 \pm 0.72^{c}$ & $\underline{73.76} \pm 0.64^{\mathrm{d}}$ & $\underline{72.42} \pm 0.68^{\mathrm{d}}$ & $<0.001$ \\
\hline \multicolumn{9}{|c|}{$20.01+0.00$} \\
\hline Male & 64 & $22.23 \pm 1.84^{\mathrm{a}}$ & $34.67 \pm 2.12^{b}$ & $49.68 \pm 2.51^{\mathrm{c}}$ & $52.67 \pm 2.04^{\mathrm{c}}$ & $\underline{69.43} \pm 1.85^{\mathrm{d}}$ & $\underline{66.52} \pm 1.97^{\mathrm{d}}$ & $<0.001$ \\
\hline Female & 497 & $23.67 \pm 0.69^{a}$ & $39.88 \pm 0.77^{b}$ & $56.60 \pm 0.73^{c}$ & $58.96 \pm 0.76^{c}$ & $74.31 \pm 0.68^{\mathrm{d}}$ & $73.18 \pm 0.71^{\mathrm{d}}$ & $<0.001$ \\
\hline$p$ Value $\S$ & & 0.567 & 0.581 & 0.259 & 0.518 & 0.182 & 0.548 & \\
\hline \multicolumn{9}{|c|}{ Age group (years) } \\
\hline $19-20$ & 112 & $24.68 \pm 1.48^{\mathrm{a}}$ & $45.10 \pm 1.41^{b}$ & $60.32 \pm 1.37^{c}$ & $63.99 \pm 1.17^{c}$ & $\underline{78.50} \pm 1.06^{\mathrm{d}}$ & $\underline{78.43} \pm 1.08^{\mathrm{d}}$ & $<0.001$ \\
\hline $21-40$ & 145 & $23.68 \pm 1.26^{a}$ & $45.54 \pm 1.37^{b}$ & $61.89 \pm 1.19^{c}$ & $66.77 \pm 1.04^{d}$ & $79.23 \pm 1.04 \mathrm{e}$ & $\underline{80.46} \pm 0.86 \mathrm{e}$ & $<0.001$ \\
\hline$\geq 41$ & 304 & $23.00 \pm 0.88^{a}$ & $34.15 \pm 0.96^{b}$ & $51.25 \pm 1.01^{\mathrm{c}}$ & $52.06 \pm 1.02^{c}$ & $\overline{69.40} \pm 0.94^{\mathrm{d}}$ & $\overline{66.37} \pm 0.98^{\mathrm{d}}$ & $<0.001$ \\
\hline$p$ Value $\S$ & & 0.304 & $<0.001$ & $<0.001$ & $<0.001$ & $<0.001$ & $<0.001$ & \\
\hline \multicolumn{9}{|c|}{ Salt intake by regional block at birth ${ }^{+}$} \\
\hline High & 138 & $22.04 \pm 1.24^{\mathrm{a}}$ & $38.67 \pm 1.54^{b}$ & $53.66 \pm 1.56^{c}$ & $54.14 \pm 1.22^{c}$ & $\underline{71.43} \pm 1.43^{\mathrm{d}}$ & $\underline{67.57} \pm 1.56^{\mathrm{d}}$ & $<0.001$ \\
\hline Middle & 204 & $22.91 \pm 1.11^{\mathrm{a}}$ & $36.86 \pm 1.12^{b}$ & $53.66 \pm 1.12^{c}$ & $56.74 \pm 1.34^{c}$ & $72.77 \pm 1.02^{d}$ & $71.38 \pm 1.06^{\mathrm{d}}$ & $<0.001$ \\
\hline Low & 219 & $25.00 \pm 1.03^{a}$ & $41.92 \pm 1.18^{b}$ & $59.26 \pm 1.11^{c}$ & $62.23 \pm 1.01^{c}$ & $76.14 \pm 0.98^{d}$ & $76.44 \pm 0.97^{\mathrm{d}}$ & $<0.001$ \\
\hline$p$ Value ${ }^{\S}$ & & 0.238 & 0.706 & 0.242 & 0.104 & 0.534 & 0.008 & \\
\hline \multicolumn{9}{|c|}{ Personal salty taste preference } \\
\hline Strong & 144 & $19.45 \pm 1.06^{\mathrm{a}}$ & $37.72 \pm 1.47^{\mathrm{b}}$ & $54.37 \pm 1.40^{c}$ & $57.40 \pm 1.32^{\mathrm{c}}$ & $\underline{73.55} \pm 1.43^{\mathrm{d}}$ & $\underline{71.94} \pm 1.23^{\mathrm{d}}$ & $<0.001$ \\
\hline Middle & 263 & $24.89 \pm 0.94^{\mathrm{a}}$ & $39.94 \pm 1.09^{b}$ & $56.71 \pm 1.07^{\mathrm{c}}$ & $58.27 \pm 1.09^{c}$ & $\overline{74.87} \pm 0.92^{\mathrm{d}}$ & $\overline{72.75} \pm 1.02^{\mathrm{d}}$ & $<0.001$ \\
\hline Light & 154 & $24.94 \pm 1.38^{a}$ & $39.63 \pm 1.29^{b}$ & $55.63 \pm 1.32^{c}$ & $58.98 \pm 1.35^{c}$ & $72.04 \pm 1.10^{\mathrm{d}}$ & $72.31 \pm 1.31^{\mathrm{d}}$ & $<0.001$ \\
\hline$p$ Value $\$$ & & 0.002 & 0.127 & 0.408 & 0.153 & 0.420 & 0.465 & \\
\hline \multicolumn{9}{|c|}{ Family salty taste preference } \\
\hline Strong & 153 & $21.22 \pm 1.15^{\mathrm{a}}$ & $40.85 \pm 1.35^{b}$ & $56.58 \pm 1.17^{c}$ & $60.38 \pm 1.30^{c}$ & $\underline{74.34} \pm 1.32^{\mathrm{d}}$ & $\underline{74.61} \pm 1.17^{\mathrm{d}}$ & $<0.001$ \\
\hline Middle & 257 & $25.24 \pm 0.98^{a}$ & $38.90 \pm 1.08^{b}$ & $55.21 \pm 1.12^{c}$ & $57.03 \pm 1.08^{c}$ & $73.67 \pm 0.93^{d}$ & $71.56 \pm 1.04^{\mathrm{d}}$ & $<0.001$ \\
\hline Light & 151 & $22.88 \pm 1.26^{\mathrm{a}}$ & $38.33 \pm 1.43^{b}$ & $56.06 \pm 1.43^{c}$ & $58.15 \pm 1.39^{c}$ & $73.30 \pm 1.20^{\mathrm{d}}$ & $71.67 \pm 1.33^{d}$ & $<0.001$ \\
\hline$p$ Value $\$$ & & 0.028 & 0.895 & 0.521 & 0.343 & 0.460 & 0.640 & \\
\hline
\end{tabular}

Values are means \pm standard errors (SEs) One underline is for the highest ratings in the $0.3 \%, 0.6 \%$, and $0.9 \% \mathrm{NaCl}$ solutions alone. Double underline is for the highest ratings in the $0.3 \%, 0.6 \%$, and $0.9 \% \mathrm{NaCl}$ solutions with MSG. The significant differences between each rating are indicated by alphabetic superscripts. A rating is significantly different from others that have different superscript letters according to Tukey's test $(p<0.05)$. +: Participants are classified into three levels according to the average salt intake by 12 regional blocks in 1980 , 1990, and 2000 from the National Nutrition Survey in Japan (low: $<12.6 \mathrm{~g}$, middle: $\geq 12.6$ and $<13.4 \mathrm{~g}$, and high: $\geq 13.4 \mathrm{~g}$ ). $\neq: p$ for repeated measures ANOVA. §: $p$ for ANCOVA adjusted for sex, age group (19-20 years, $21-40$ years, and $\geq 41$ years), smoking habit (current, former, and never), salt reduction efforts (always, sometimes, and rarely/never), and use of medicine (yes and no).

\subsection{Palatability}

The means and SEs of palatability VAS ratings by sex, age groups, the three levels of salt intake by regional block at birth, and the three levels of salty taste preference are shown in Table 4. Repeated measures ANOVA results showed significant differences in the average ratings of the six solutions among all groups based on sex, age groups, the three levels of salt intake by regional block at birth, and the three levels of salty taste preference (all $p<0.001$ ). The results of the post-hoc test showed that the $0.3 \%, 0.6 \%$, and $0.9 \% \mathrm{NaCl}$ solutions with MSG showed significantly higher ratings for palatability than those without MSG among all groups (all $p<0.05$ ), except for the rating of the $0.9 \% \mathrm{NaCl}$ solution in the male group $(p=0.069)$. Regardless of age groups, salt intake by regional block at birth, and salty taste preference, adding MSG significantly enhanced the solutions' palatability. The palatability ratings of the $0.3 \% \mathrm{NaCl}$ solution with MSG were almost twice as high as those of the $0.3 \% \mathrm{NaCl}$ solution without MSG in all groups. Moreover, the palatability ratings of the $0.3 \% \mathrm{NaCl}$ solution with MSG were the highest among the six solutions in the female group, while there was no significant difference between the rating of the $0.3 \% \mathrm{NaCl}$ solution with MSG and $0.6 \% \mathrm{NaCl}$ solution with MSG in the male group, the three age groups, the three levels of salt intake by regional block at birth, and the three levels of salty taste preference. ANCOVA results showed significantly different ratings for palatability among age groups for the $0.6 \% \mathrm{NaCl}$ solution without MSG $(p=0.040)$, with the rating of the over 41-years-old age group being lower than that of the other two groups. There were significantly different ratings for palatability among the three levels of personal salty taste preference for the $0.9 \% \mathrm{NaCl}$ solution with MSG $(p=0.007)$, with the rating of the light group being lower than that of the other groups. Additionally, peak ratings of palatability were expressed for the $0.3 \% \mathrm{NaCl}$ solutions with MSG, and there were no significant differences in palatability ratings among the solutions having peak ratings in each group (sex, $p=0.273$; age groups, $p=0.147$; salt intake by regional block 
at birth, $p=0.642$; personal salty taste preference, $p=0.624$; family salty taste preference, and $p=0.989$ ). Among the $0.3 \%, 0.6 \%$, and $0.9 \% \mathrm{NaCl}$ solutions without MSG, the $0.6 \%$ $\mathrm{NaCl}$ solution had the highest palatability rating in all groups except for the male group, which had a peak rating for the $0.9 \% \mathrm{NaCl}$ solution. Among the $0.3 \%, 0.6 \%$, and $0.9 \%$ $\mathrm{NaCl}$ solutions with MSG, the $0.3 \% \mathrm{NaCl}$ solution had the highest rating across all groups. Moreover, all solutions with MSG had peak ratings at a lower $\mathrm{NaCl}$ concentration than the solutions without MSG, regardless of sex, age, levels of salt exposure environment in early childhood, and salty taste preference.

Table 4. Palatability VAS ratings by sex, age, salt intake by regional block at birth, and salty taste preference.

\begin{tabular}{|c|c|c|c|c|c|c|c|c|}
\hline & \multirow[b]{2}{*}{$N$} & \multicolumn{2}{|c|}{$0.3 \% \mathrm{NaCl}$} & \multicolumn{2}{|c|}{$0.6 \% \mathrm{NaCl}$} & \multicolumn{2}{|c|}{$0.9 \% \mathrm{NaCl}$} & \multirow[b]{2}{*}{$p$ Value $\ddagger$} \\
\hline & & -MSG & +MSG & -MSG & +MSG & -MSG & +MSG & \\
\hline All & 561 & $30.66 \pm 0.78^{a}$ & $\underline{60.95} \pm 0.90^{\mathrm{b}}$ & $\underline{44.87} \pm 0.71^{\mathrm{c}}$ & $57.62 \pm 0.75^{\mathrm{d}}$ & $40.76 \pm 0.75^{\mathrm{e}}$ & $51.81 \pm 0.83^{\mathrm{f}}$ & $<0.001$ \\
\hline \multicolumn{9}{|l|}{ Sex } \\
\hline Male & 64 & $29.18 \pm 2.34^{\mathrm{a}}$ & $\underline{56.41} \pm 2.58^{b}$ & $39.81 \pm 2.04^{\mathrm{c}}$ & $55.16 \pm 1.75^{b}$ & $\frac{41.52}{4066} \pm 2.11^{\mathrm{cd}}$ & $50.20 \pm 2.48^{b d}$ & $<0.001$ \\
\hline Female & 497 & $30.85 \pm 0.83^{\mathrm{a}}$ & $\underline{61.54} \pm 0.96^{\mathrm{b}}$ & $\underline{45.52} \pm 0.75^{\mathrm{c}}$ & $57.94 \pm 0.82^{\mathrm{d}}$ & $40.66 \pm 0.80^{\mathrm{e}}$ & $52.01 \pm 0.89^{\mathrm{f}}$ & $<0.001$ \\
\hline$p$ Value ${ }^{\S}$ & & 0.695 & 0.273 & 0.078 & 0.409 & 0.544 & 0.319 & \\
\hline \multicolumn{9}{|c|}{ Age group (years) } \\
\hline $19-20$ & 112 & $32.48 \pm 1.49^{a}$ & $\underline{59.57} \pm 1.86^{\mathrm{b}}$ & $\underline{46.36} \pm 1.39 \mathrm{~cd}$ & $56.58 \pm 1.65$ be & $41.44 \pm 1.49^{c}$ & $51.53 \pm 1.97^{\mathrm{de}}$ & $<0.001$ \\
\hline $21-40$ & 145 & $31.60 \pm 1.73^{\mathrm{a}}$ & $\underline{\underline{63.66}} \pm 1.88^{\mathrm{b}}$ & $\underline{\overline{48.45}} \pm 1.44^{\mathrm{cd}}$ & $60.16 \pm 1.54^{b}$ & $43.35 \pm 1.48^{c}$ & $51.47 \pm 1.76^{\mathrm{d}}$ & $<0.001$ \\
\hline$\geq 41$ & 304 & $29.54 \pm 1.05^{\mathrm{a}}$ & $\overline{60.17} \pm 1.22^{b}$ & $\underline{42.61} \pm 0.97^{\mathrm{c}}$ & $56.80 \pm 1.00^{\mathrm{b}}$ & $39.27 \pm 1.06^{c}$ & $52.07 \pm 1.07^{\mathrm{d}}$ & $<0.001$ \\
\hline$p$ Value $\S$ & & 0.154 & 0.147 & 0.040 & 0.230 & 0.175 & 0.399 & \\
\hline \multicolumn{9}{|c|}{ Salt intake by regional block at birth ${ }^{+}$} \\
\hline High & 138 & $32.70 \pm 1.67^{\mathrm{a}}$ & $\underline{59.33} \pm 1.69^{\mathrm{b}}$ & $\underline{46.34} \pm 1.43^{\mathrm{cd}}$ & $57.48 \pm 1.62$ be & $41.29 \pm 1.56^{\mathrm{c}}$ & $52.69 \pm 1.68^{\mathrm{de}}$ & $<0.001$ \\
\hline Middle & 204 & $28.19 \pm 1.20^{\mathrm{a}}$ & $\underline{61.60} \pm 1.56^{\mathrm{b}}$ & $\underline{43.42} \pm 1.24^{\mathrm{c}}$ & $57.11 \pm 1.24^{\mathrm{b}}$ & $39.60 \pm 1.29^{d}$ & $51.45 \pm 1.32^{\mathrm{c}}$ & $<0.001$ \\
\hline Low & 219 & $31.67 \pm 1.27^{\mathrm{a}}$ & $61.37 \pm 1.45^{\mathrm{b}}$ & $45.29 \pm 1.07^{c}$ & $58.19 \pm 1.15^{\mathrm{b}}$ & $41.50 \pm 1.15^{\mathrm{c}}$ & $51.58 \pm 1.39^{\mathrm{d}}$ & $<0.001$ \\
\hline$p$ Value $\$$ & & 0.099 & 0.642 & 0.246 & 0.877 & 0.743 & 0.845 & \\
\hline \multicolumn{9}{|c|}{ Personal salty taste preference } \\
\hline Strong & 144 & $28.23 \pm 1.40^{\mathrm{a}}$ & $\underline{61.40} \pm 1.79^{\mathrm{b}}$ & $\underline{45.04} \pm 1.36^{\mathrm{c}}$ & $58.73 \pm 1.31 \mathrm{bd}$ & $43.34 \pm 1.49^{c}$ & $55.26 \pm 1.53^{\mathrm{d}}$ & $<0.001$ \\
\hline Middle & 263 & $30.75 \pm 1.13^{\mathrm{a}}$ & $\overline{61.92} \pm 1.31^{\mathrm{b}}$ & $\overline{\underline{44.64}} \pm 1.05^{\mathrm{c}}$ & $58.99 \pm 1.09^{b}$ & $40.34 \pm 1.13^{c}$ & $52.17 \pm 1.22^{\mathrm{d}}$ & $<0.001$ \\
\hline Light & 154 & $32.77 \pm 1.62^{a}$ & $\overline{\underline{58.88}} \pm 1.72^{b}$ & $\underline{\overline{45.09}} \pm 1.37^{\mathrm{cd}}$ & $54.26 \pm 1.57^{b}$ & $39.06 \pm 1.34^{c}$ & $47.97 \pm 1.65^{\mathrm{d}}$ & $<0.001$ \\
\hline$p$ value $\S$ & & 0.085 & 0.624 & 0.702 & 0.082 & 0.317 & 0.007 & \\
\hline \multicolumn{9}{|c|}{ Family salty taste preference } \\
\hline Strong & 153 & $30.29 \pm 1.54^{a}$ & $\underline{61.77} \pm 1.70^{\mathrm{b}}$ & $\underline{47.07} \pm 1.19^{\mathrm{cd}}$ & $58.26 \pm 1.36^{\mathrm{b}}$ & $43.35 \pm 1.43^{c}$ & $51.77 \pm 1.57^{\mathrm{d}}$ & $<0.001$ \\
\hline Middle & 257 & $30.87 \pm 1.11^{\mathrm{a}}$ & $\overline{60.89} \pm 1.31^{b}$ & $\underline{44.32} \pm 1.08^{c}$ & $57.88 \pm 1.11^{b}$ & $41.13 \pm 1.11^{c}$ & $52.45 \pm 1.23^{\mathrm{d}}$ & $<0.001$ \\
\hline Light & 151 & $30.67 \pm 1.58^{a}$ & $\overline{60.22} \pm 1.81^{b}$ & $\underline{\overline{43.57}} \pm 1.45^{\mathrm{c}}$ & $56.54 \pm 1.53^{\mathrm{bd}}$ & $37.51 \pm 1.44^{c}$ & $50.75 \pm 1.66^{d}$ & $<0.001$ \\
\hline$p$ Value ${ }^{\S}$ & & 0.843 & 0.989 & 0.497 & 0.935 & 0.096 & 0.830 & \\
\hline
\end{tabular}

Values are means \pm standard errors (SEs). One underline is for the highest ratings in the $0.3 \%, 0.6 \%$, and $0.9 \% \mathrm{NaCl}$ solutions alone. Double underline is for the highest ratings in the $0.3 \%, 0.6 \%$, and $0.9 \% \mathrm{NaCl}$ solutions with MSG. The significant differences between each rating are indicated by alphabetic superscripts. A rating is significantly different from others that have different superscript letters according to Tukey's test $(p<0.05)$. +: Participants are classified into three levels according to the average salt intake by 12 regional blocks in 1980 , 1990, and 2000 from the National Nutrition Survey in Japan (low: $<12.6 \mathrm{~g}$, middle: $\geq 12.6$ and $<13.4 \mathrm{~g}$, and high: $\geq 13.4 \mathrm{~g}$ ). $\neq: p$ for repeated measures ANOVA. §: $p$ for ANCOVA adjusted for sex, age group (19-20 years, $21-40$ years, and $\geq 41$ years), smoking habit (current, former, and never), salt reduction efforts (always, sometimes, and rarely/never), and use of medicine (yes and no).

\section{Discussion}

This study demonstrated that MSG enhanced the palatability of low-salt solutions, regardless of sex, age, salt intake by regional block at birth, and salty taste preference. Additionally, the $0.3 \% \mathrm{NaCl}$ solution with MSG showed peak values of palatability ratings regardless of sex, age, salt intake by regional block at birth, and salty taste preference. This is the first study to investigate the effect of MSG, that is, umami ingredients, on low-salt solutions while considering the difference between the salt exposure environment in early childhood and current salty taste preference.

In a previous study, we presented the results of 584 participants evaluating six solutions $(0.3 \%, 0.6 \%$, and $0.9 \% \mathrm{NaCl}$ solutions with or without $0.3 \% \mathrm{MSG})$; the results suggested that MSG enhanced the palatability of low-salt solutions regardless of sex, age, region, smoking habit, two hours of fasting, and medication [25]. The present study investigated the effect of MSG on low-sodium solutions, based on the variables of sex, age, levels of salt exposure environment in early childhood, and on salty taste preferences to contribute to the generalization of the effects of MSG.

In this study, it was shown that saltiness ratings depended on $\mathrm{NaCl}$ concentration of the solution, while palatability ratings were independent of $\mathrm{NaCl}$ concentration and got the peak value at a lower $\mathrm{NaCl}$ concentration $(0.3 \% \mathrm{NaCl}$ with $0.3 \% \mathrm{MSG})$ than the 
general concentration (around $1.0 \% \mathrm{NaCl}$ ) at which Japanese individuals consumed soup. In the previous studies investigating the interaction of $\mathrm{NaCl}$ and umami (MSG or CDG) in different types of soups, it was shown that the saltiness depended on $\mathrm{NaCl}$ concentration of the solution, while palatability ratings appeared parabolic wherein the peaks were observed at a different, medium-salty $\mathrm{NaCl}$ concentration [17-19]. Our results were broadly consistent with these previous reports.

A significant enhancing effect was observed for saltiness by adding MSG in the $0.3 \%$ $\mathrm{NaCl}$ solution regardless of sex, age, salt intake by regional block at birth, and salty taste preference. Although the detailed mechanism has not been clarified, it is known that saltiness sensitivity decreases with aging $[29,30]$. Barragan et al. conducted an evaluation test on participants aged 18-80 years, and reported that the 37-50-year-old and 51-80year-old groups had a significantly reduced salty taste compared to the 18-36-year-old group [31]. In this study, the saltiness ratings of the over 41-years-old age group were lower than those of the other two younger age groups, a trend consistent with previous studies [29-31]. For the level of salt intake by regional block at birth, the saltiness ratings of the low-level group for the $0.9 \% \mathrm{NaCl}$ solution with MSG were higher than those of the other groups. This means that those who were exposed to low levels of salt in early childhood were more sensitive to salty taste than those exposed to high salt levels. These results support previous studies reporting that taste preferences established under the influence of food experiences in early childhood continue through life [11,12].

In our previous study, MSG enhanced ratings of the $0.3 \%, 0.6 \%$, and $0.9 \% \mathrm{NaCl}$ solutions on palatability, and the $0.3 \% \mathrm{NaCl}$ solution with MSG showed the highest palatability ratings. In addition, we suggested that it might be possible for the $0.3 \% \mathrm{NaCl}$ solution with MSG (Na: $0.391 \mathrm{~g} / \mathrm{mL}$ ) to have a reduction of approximately $60 \%$ sodium compared to the $0.9 \% \mathrm{NaCl}$ solution with MSG (Na: $0.155 \mathrm{~g} / \mathrm{mL}$ ) without a loss of palatability [25]. In the present study, MSG significantly enhanced the palatability ratings of the $0.3 \%, 0.6 \%$, and $0.9 \% \mathrm{NaCl}$ solutions among all groups, with the exception of the $0.9 \% \mathrm{NaCl}$ solution in male. Moreover, the rating for the $0.3 \% \mathrm{NaCl}$ solution with MSG showed the highest palatability regardless of sex, age, salt intake by regional block at birth, and salty taste preference. The enhanced effect of MSG was the same in the over 41-year-old age group with a weakened salty perception as in the other two younger age groups. As for palatability in males, the $0.9 \% \mathrm{NaCl}$ solution obtained the peak rating among the three solutions of $\mathrm{NaCl}$ without MSG, and this rating was higher than that given by female and groups based on other classifications. While the sense of palatability in males might be low, the peak rating for palatability shifted from the $0.9 \%$ to $0.3 \% \mathrm{NaCl}$ solution due to the addition of MSG. This indicates that adding MSG might be effective in reducing salt intake in males.

In this study, we investigated the influence of salt exposure environment in early childhood on the palatability using MSG on low-salt solutions. Our results showed that early childhood salt exposure did not affect enhancement of palatability using MSG in low-salt solutions. Kobayashi et al. have shown that sensitivity to umami taste is largely dependent on familiarity with umami taste [21]. As the Japanese participants had extensive experience with MSG in Japanese food, they might have been sensitive to the effect of umami ingredients on palatability.

We also assessed the influence of the degree of salty taste preference of individuals and families on sensory evaluation results. Regarding palatability, the ratings of the $0.3 \%$ $\mathrm{NaCl}$ solution with MSG showed a peak in all groups regardless of the degree of salty taste preference. Comparing the peak ratings among the strong, middle, and light groups, no significant difference was found. Uechi et al. examined urinary sodium excretion among participants in 47 prefectures of Japan and reported no domestic fluctuation [32]. In 1980, there was a difference in salt intake of about $5 \mathrm{~g} /$ day by regional block in Japan, from the highest (Tohoku: $15.8 \mathrm{~g} /$ day) salt-consuming region to the lowest (Kinki-1: $10.9 \mathrm{~g} /$ day) (Table 1). However, in 2018, the difference was only $1.6 \mathrm{~g} /$ day (the highest salt-consuming region, Tohoku: $11.1 \mathrm{~g} /$ day and the lowest salt-consuming region, Hokkaido/ Shikoku: $9.5 \mathrm{~g} /$ day), indicating that the regional differences in salt intake are becoming smaller [33]. 
This may be due to the influence of social development and the westernization of the Japanese diet [32].

The members of the WHO have committed to reducing the salt intake by $30 \%$ by 2025 [34]. Sustainable Development Goal Number 3 states that premature mortality from non-communicable diseases will be reduced to one-third by 2030 [35]. Each country has set out policies for the food service industry and processed food manufacturers to reduce the salt content of their products. In the United Kingdom, the Salt Reduction Program has been led by the Department of Health since 2003. This program has reduced salt intake from $9.5 \mathrm{~g} /$ day in 2000-2001 to $8.1 \mathrm{~g} /$ day in 2008 [36]. In 2018, the Spanish Agency for Consumer Affairs, Food and Nutrition released the Collaboration Plan for the Improvement of the Composition of Food and Beverages, which committed to reducing salt content in various food categories [37]. In Japan, the Health Japan 21 (second term) program aims at curtailing salt intake to $8 \mathrm{~g} /$ day [38]; however, there is no policy for the food industry regarding salt reduction. Although average salt intake in Japan has decreased due to medical and administrative population policy approaches, it has remained almost unchanged since 2015. The National Health and Nutrition Survey in 2019 investigated the intention to improve dietary habits, and more than $30 \%$ of the respondents answered they did not intend to improve their dietary habits even if they were consuming over $8 \mathrm{~g} /$ day salt [6]. In addition to a population approach, incorporating an environmental approach, such as working with the food industry to reduce the amount of sodium in their products, is also important in managing salt intake $[39,40]$. The Japanese Society of Hypertension has begun to work on an environmental approach toward reducing salt intake, such as including a certification for food items with a low salt content [41]. Moreover, 13 academic societies in Japan have formed a consortium, and a certification system for healthy and nutritional meal patterns (common name: Smart Meal) was launched in December 2019 in Japan. Smart Meal aims at restricting salt intake to $3.0-3.5 \mathrm{~g} /$ meal [42], which is expected to bring in environmental benefits as well.

Wallace et al. estimated the effect of using glutamates to substitute the amount of sodium among certain food groups in America, and reported that doing so could have a modest effect on the salt intake of the whole American population [43]. Some studies on animal models reported that adding MSG was associated with higher energy intake and obesity, while clinical and epidemiological studies have been inconsistent regarding a relationship between MSG consumption and energy intake and obesity [44]: Masic et al. reported adding MSG increased immediate appetite but reduced subsequent test meal intake [45], and He et al. reported MSG consumption was positively associated with BMI [46]. The effect of MSG on appetite is currently unclear, thus the effect of salt reduction using MSG would be expected to be more beneficial even considering the effect on appetite. Utilizing low-salt soups using umami, regardless of sex, age, salt exposure environment in early childhood, and current salty taste preference, will be useful to work toward an environmental approach to reducing salt intake.

This study had a few limitations. First, the participants of this study were registered students being trained as dietitians and health seminar participants and hence, likely to have been a highly health conscious group, which might have influenced the results. In addition, the proportion of female participants was high, and the number of people in each of the 12 regional blocks was unequal. In order to further generalize the data, it will be necessary to conduct a survey of populations with a wide range of characteristics. Second, in this study, the salt exposure environment in early childhood was defined as the average salt intake by regional block at birth in 1980, 1990, and 2000. However, the actual salt intake of each individual might differ. Furthermore, the average salt intakes by regional block at birth in 1980, 1990, and 2000 were quoted from the results of the National Nutrition Survey, but the sodium amount calculation method differs in each survey [9]. However, when examining food composition data, it is desirable that using better technologies, a more optimal method for obtaining an accurate intake is selected, as the old data cannot accurately calculate the current intake. This is a drawback when 
long-term investigations are conducted. Finally, we applied the data for the year 1980 to participants born before 1980 because no data on salt intake at birth were available before the year of 1980. The Japanese salt intake in 1980 was $12.9 \mathrm{~g} /$ day, while in 1975 it was $13.5 \mathrm{~g}$ /day [9]. Therefore, the salt intake by regional block before 1980 was also considered higher than in 1980.

\section{Conclusions}

There was no difference in the effect of umami ingredients on palatability between average salt intake by the regional block at birth and salty taste preference. These findings suggest that adding an appropriate amount of umami ingredients can facilitate salt reduction while maintaining palatability, regardless of early childhood salt exposure environment and current salty preference. If an environment is created in which umami is effectively utilized to reduce salt intake, it could be useful in the prevention and management of hypertension, and might contribute to a reduction in the incidence and mortality of cardiovascular disease as well.

Author Contributions: R.M., M.O., and H.H. conceived and designed the study; Y.U., A.N., T.T., and H.H. recruited participants; R.M. and H.H. obtained the data; R.M., M.O., and H.H. analyzed the data; R.M. and M.O. performed the statistical analyses; R.M., M.O., and H.H. wrote the paper. All authors have read and agreed to the published version of the manuscript.

Funding: This research was funded by Ajinomoto Co., Inc. from 2015 to 2019, and by the Society for Research on Umami Taste (grant number: SRUT201925).

Institutional Review Board Statement: The study was conducted according to the guidelines of the Declaration of Helsinki, and approved by the Research Ethics Committee at Fukuoka Women's University (No. 2016-31 and 31 March 2017) for students and the Research Ethics Review Committee at Nara Women's University (No. 18-02 and 21 June 2018) for attendees of health seminars.

Informed Consent Statement: Informed consent was obtained from all subjects involved in the study.

Acknowledgments: The authors would like to thank all study staff for their substantial efforts and all participants for their cooperation. The authors sincerely thank Sadayoshi Ito (Tohoku Univ./Department of Medicine, Katta General Hospital), Atsushi Sakima (Univ. of the Ryukyus), Hiroyuki Takase (Eishu Hospital), Miho Kusaka (Kusaka Clinic), Toshinao Goda (Univ. of Shizuoka), Tomoko Watanabe (Shukutoku Univ.), Tomoko Ohno (Aomori Univ. of Health and Welfare), Saori Shimada (Yasuda Women's Univ.), Chiharu Tsutsumi (Sagami Women's Univ.), Kayoko Imamura (Kagoshima Immaculate Heart Univ.), Hinano Okamoto (Nara Women's Univ.), Yumie Konno (Miyagi), Fujiko Miyahara (Tokyo and Saitama), Toshiyuki Sato (Nara), Yuko Nishi (Kitakyushu), Michiyo Shibata (Munakata), and Haruko Konishi (Nagasaki) for conducting the survey in each region. We are also grateful to Hisatoshi Uneyama (Ajinomoto Co., Inc.) and the Society for Research on Umami Taste for support related to the study.

Conflicts of Interest: Yoko Umeki and Takuya Tsuchihashi declare no conflict of interest. Rieko Morita and Masanori Ohta received research grants from the Society for Research on Umami Taste (grant number: SRUT201925). Hitomi Hayabuchi received a research grant from Ajinomoto Co., Inc. from 2015 to 2019, and Rieko Morita and Akiko Nanri joined this organization from 2017 to 2018.

\section{References}

1. Asaria, P.; Chisholm, D.; Mathers, C.; Ezzati, M.; Beaglehole, R. Chronic disease prevention: Health effects and financial costs of strategies to reduce salt intake and control tobacco use. Lancet 2007, 370, 2044-2053. [CrossRef]

2. Bibbins-Domingo, K.; Chertow, G.M.; Coxson, P.G.; Moran, A.; Lightwood, J.M.; Pletcher, M.J.; Goldman, L. Projected effect of dietary salt reductions on future cardiovascular disease. N. Engl. J. Med. 2010, 362, 590-599. [CrossRef] [PubMed]

3. Mozaffarian, D.; Fahimi, S.; Singh, G.M.; Micha, R.; Khatibzadeh, S.; Engell, R.E.; Lim, S.; Danaei, G.; Ezzati, M.; Powles, J. Global Sodium consumption and death from cardiovascular causes. N. Engl. J. Med. 2014, 371, 624-634. [CrossRef] [PubMed]

4. Afshin, A.; Sur, P.J.; Fay, K.A.; Cornaby, L.; Ferrara, G.; Salama, J.S.; Mullany, E.C.; Abate, K.H.; Abbafati, C.; Abebe, Z.; et al. Health effects of dietary risks in 195 countries, 1990-2017: A systematic analysis for the global burden of disease study 2017. Lancet 2019, 393, 1958-1972. [CrossRef] 
5. He, F.J.; Brown, M.; Tan, M.; MacGregor, G.A. Reducing population salt intake-An update on latest evidence and global action. J. Clin. Hypertens. 2019, 00,1-6. [CrossRef]

6. Ministry of Health, Labour and Welfare. Summary of Results from the National Health and Nutrition Survey 2019. Available online: https:/ /www.mhlw.go.jp/stf/newpage_14156.html (accessed on 17 November 2020).

7. Ministry of Health, Labour and Welfare. Vital Statistics in Japan-Trends up to 2016. Available online: https://www.mhlw.go.jp/ toukei/list/dl/81-1a2.pdf (accessed on 17 November 2020).

8. Tomonari, T.; Fukuda, M.; Miura, T.; Mizuno, M.; Wakamatsu, Y.T.; Ichikawa, T.; Miyagi, S.; Shirasawa, Y.; Ito, A.; Yoshida, A.; et al. Is salt intake an independent risk factor of stroke mortality? Demographic analysis by regions in Japan. J. Am. Soc. Hypertens. 2011, 5, 456-462. [CrossRef]

9. Ministry of Health, Labour and Welfare. The National Nutrition Survey 1950-2002. Available online: https://www.nibiohn.go. jp/eiken/chosa/kokumin_eiyou/ (accessed on 25 September 2020).

10. Takachi, R.; Ishihara, J.; Iwasaki, M.; Ishii, Y.; Tsugane, S. Self-reported taste preference can be a proxy for daily sodium intake in middle-aged Japanese adults. J. Acad. Nutr. Diet. 2014, 114, 781-787. [CrossRef]

11. Ventura, A.K.; Worobey, J. Early influences on the development of food preferences. Curr. Biol. 2013, 23, R401-R408. [CrossRef]

12. Mennella, J.A. Ontogeny of taste preferences: Basic biology and implications for health1-5. Am. J. Clin. Nutr. 2014, 99, 704S-711S. [CrossRef]

13. Ikehara, S.; Iso, H.; Date, C.; Kikuchi, S.; Watanabe, Y.; Inaba, Y.; Tamakoshi, A.; The JACC Study Group. Salt preference and mortality from stroke and coronary heart disease for Japanese men and women: The JACC study. Prev. Med. 2012, 54, 32-37. [CrossRef]

14. Mattes, R. The taste for salt in humans. Am. J. Clin. Nutr. 1997, 65, 692S-697S. [CrossRef] [PubMed]

15. WHO/FAO Expert Consultation. Diet, Nutrition, and the Prevention of Chronic Diseases: Report of a Joint WHO/FAO Expert Consultation; World Health Organization: Geneva, Switzerland, 2003; ISBN 924120916X.

16. Institute of Medicine. Strategies to Reduce Sodium Intake in the United States; Henney, J.E., Taylor, C.L., Boon, C.S., Eds.; The National Academies Press: Washington, DC, USA, 2010; ISBN 9780309148054.

17. Yamaguchi, S.; Takahashi, C. Interactions of monosodium glutamate and sodium chloride on saltiness and palatability of a clear soup. J. Food Sci. 1984, 49, 82-85. [CrossRef]

18. Ball, P.; Woodward, D.; Beard, T.; Shoobridge, A.; Ferrier, M. Calcium diglutamate improves taste characteristics of lower-salt soup. Eur. J. Clin. Nutr. 2002, 56, 519-523. [CrossRef] [PubMed]

19. Carter, B.E.; Monsivais, P.; Drewnowski, A. The sensory optimum of chicken broths supplemented with calcium di-glutamate: A possibility for reducing sodium while maintaining taste. Food Qual. Prefer. 2011, 22, 699-703. [CrossRef]

20. Shigemura, N.; Shirosaki, S.; Sanematsu, K.; Yoshida, R.; Ninomiya, Y. Genetic and molecular basis of individual differences in human umami taste perception. PLoS ONE 2009, 4, e6717. [CrossRef]

21. Kobayashi, C.; Linda, M.K.; Bruce, P.H. Experience-induced changes in taste identification of monosodium glutamate (MSG) are reversible. Chem. Sens. 2006, 31, 301-306. [CrossRef]

22. Singh, P.B.; Hummel, T.; Gerber, J.C.; Landis, B.N.; Iannilli, E. Cerebral processing of umami: A pilot study on the effects of familiarity. Brain. Res. 2015, 1614, 67-74. [CrossRef]

23. Loper, H.B.; La Sala, M.; Dotson, C.; Steinle, N. Taste perception, associated hormonal modulation, and nutrient intake. Nutr. Rev. 2015, 73, 83-91. [CrossRef]

24. Han, P.; Mohebbi, M.; Unrath, M.; Hummel, C.; Hummel, T. Different neural processing of umami and salty taste determined by umami identification ability independent of repeated umami exposure. Neuroscience 2018, 383, 74-83. [CrossRef]

25. Hayabuchi, H.; Morita, R.; Ohta, M.; Nanri, A.; Matsumoto, H.; Fujitani, S.; Yoshida, S.; Ito, S.; Sakima, A.; Takase, H.; et al. Validation of preferred salt concentration in soup based on a randomized blinded experiment in multiple regions in Japan-influence of umami (L-glutamate) on saltiness and palatability of low-salt solutions. Hypertens. Res. 2020, 43, 525-533. [CrossRef] [PubMed]

26. Morita, R.; Ohta, M.; Hayabuchi, H.; Fujitani, S.; Yoshida, S.; Matsumoto, H.; Tsuchihashi, T. Quantitative verification of the effect of using an umami substance (L-glutamate) to reduce salt intake. Hypertens. Res. 2020, 43, 579-581. [CrossRef] [PubMed]

27. Flint, A.; Raben, A.; Blundell, J.E.; Astrup, A. Reproducibility, power and validity of visual analogue scales in assessment of appetite sensations in single test meal studies. Int. J. Obes. 2000, 24, 38-48. [CrossRef] [PubMed]

28. Gillian, Z.H.; Maurizio, M.; Roberta, C. How to analyze the visual analogue scale: Myths, truths and clinical relevance. Scand. J. Pain. 2016, 13, 67-75. [CrossRef]

29. Mojet, J.; Christ-Hazelhof, E.; Heidema, J. Taste perception with age: Generic or specific losses in threshold sensitivity to the five basic tastes? Chem. Sens. 2001, 26, 845-860. [CrossRef]

30. Yoshinaka, M.; Ikebe, K.; Uota, M.; Ogawa, T.; Okada, T.; Inomata, C.; Takeshita, H.; Mihara, Y.; Gondo, Y.; Masui, Y.; et al. Age and sex differences in the taste sensitivity of young adult, young-old and old-old Japanese. Geriatr. Gerontol. 2016, 16, 1281-1288. [CrossRef]

31. Barragán, R.; Coltell, O.; Portolés, O.; Asensio, E.M.; Sorlí, J.V.; Ortega-Azorín, C.; González, J.I.; Sáiz, C.; Fernández-Carrión, R.; Ordovas, J.M.; et al. Bitter, sweet, salty, sour and umami taste perception decreases with age: Sex-specific analysis, modulation by genetic variants and taste-preference associations in 18 to 80 year-old subjects. Nutrients 2018, 10, 1539. [CrossRef]

32. Uechi, K.; Asakura, K.; Masayasu, S.; Sasaki, S. Within-country variation of salt intake assessed via urinary excretion in Japan: A multilevel analysis in all 47 prefectures. Hypertens. Res. 2017, 40, 598-605. [CrossRef] 
33. Ministry of Health, Labour and Welfare. The National Health and Nutrition Survey 2018. Available online: https://www.mhlw. go.jp/content/10900000/000687163.pdf (accessed on 23 November 2020).

34. World Health Organization. Global Action Plan for the Prevention and Control of Non-Communicable Diseases 2013-2020. Available online: https:/ /apps.who.int/iris/bitstream/handle/10665/94384/9789241506236_eng.pdf;jsessionid=0539258C0F6 CD5CDFABF9455ACAAEC28? sequence=1 (accessed on 18 November 2020).

35. United Nations. Take Action for the Sustainable Development Goals-United Nations Sustainable Development. Available online: https: / /www.un.org/sustainabledevelopment/sustainable-development-goals/ (accessed on 30 November 2020).

36. He, F.J.; Pombo-Rodrigues, S.; MacGregor, G.A. Salt reduction in England from 2003 to 2011: Its relationship to blood pressure, stroke and ischaemic heart disease mortality. BMJ Open 2014, 4, e004549. [CrossRef]

37. The Spanish Agency for Consumer Affairs Food Safety and Nutrition (AECOSAN). Collaboration PLAN for the Improvement of the Composition of Food and Beverages and Other Measures. Available online: https://www.aesan.gob.es/AECOSAN/docs/ documentos/nutricion/Plan_Colaboracion_INGLES.pdf (accessed on 24 November 2020).

38. Ministry of Health, Labour and Welfare. A Basic Direction for Comprehensive Implementation of National Health Promotion. Available online: https:/ / www.mhlw.go.jp/ file/06-Seisakujouhou-10900000-Kenkoukyoku/0000047330.pdf (accessed on 7 December 2020).

39. Asakura, K.; Uechi, K.; Masayasu, S.; Sasaki, S. Sodium sources in the Japanese diet: Difference between generations and sexes. Publ. Health Nutr. 2016, 19, 2011-2023. [CrossRef] [PubMed]

40. Okuda, N.; Stamler, J.; Brown, I.J.; Ueshima, H.; Miura, K.; Okayama, A.; Saitoh, S.; Nakagawa, H.; Sakata, K.; Yoshita, K.; et al. Individual efforts to reduce salt intake in China, Japan, UK, USA: What did people achieve? the INTERMAP population study. $J$. Hypertens. 2014, 32, 2385-2392. [CrossRef] [PubMed]

41. Tsuchihashi, T. Practical and personal education of dietary therapy in hypertensive patients. Hypertens. Res. 2020, 43, 6-12. [CrossRef] [PubMed]

42. Ministry of Agriculture, Forestry and Fisheries. Policies for the Promotion of Shokuiku (White Paper on Shokuiku) The Fiscal Year 2018 Edition [Summary]. Available online: https://www.maff.go.jp/j/syokuiku/wpaper/attach/pdf/h30_index-21.pdf (accessed on 3 December 2020).

43. Wallace, T.C.; Cowan, A.E.; Bailey, R.L. Current sodium intakes in the United States and the modelling of glutamate's incorporation into select savory products. Nutrients 2019, 11, 2691. [CrossRef] [PubMed]

44. Anca, Z.; Anca, U.; Aristides, M.T.; George, M.N.; Demetrios, K.; Aris, V.; Dimitrios, T.; Ayse, B.E.; Michael, A.; Denisa, M. A review of the alleged health hazards of monosodium glutamate. Compr. Rev. Food Sci. F. 2019, 18, 1111-1134. [CrossRef]

45. Una, M.; Martin, R.Y. Umami flavor enhances appetite but also increases satiety. Am. J. Clin. Nutr. 2014, 100, 532-538. [CrossRef]

46. He, K.; Zhao, L.; Daviglus, M.L.; Dyer, A.R.; Van Horn, L.; Garside, D.; Zhu, L.; Guo, D.; Wu, Y.; Zhou, B.; et al. Association of monosodium glutamate intake with overweight in Chinese adults: The INTERMAP study. Obesity 2008, 16, 1875-1880. [CrossRef] 